\title{
Atenção hospitalar ao recém-nascido saudável no Brasil: estamos avançando na garantia das boas práticas?
}

\author{
Care for healthy newborns in Brazil: are we making progress \\ in achieving best practices?
}

Maria Auxiliadora de Souza Mendes Gomes (https://orcid.org/0000-0001-5908-1763) ${ }^{1}$

Ana Paula Esteves-Pereira (https://orcid.org/0000-0002-0236-2043) ${ }^{2}$

Sonia Duarte de Azevedo Bittencourt (https://orcid.org/0000-0003-2466-1797) ${ }^{2}$

Liliane Cristina Rodrigues Augusto (https://orcid.org/0000-0002-8164-5577) ${ }^{3}$

Fernando Lamy-Filho (https://orcid.org/0000-0002-7858-4195) ${ }^{4}$

Zeni Carvalho Lamy (https://orcid.org/0000-0002-9332-0542) ${ }^{5}$

Cynthia Magluta (https://orcid.org/0000-0002-6630-3763) ${ }^{1}$

Maria Elisabeth Moreira (https://orcid.org/0000-0002-2034-0294) ${ }^{1}$

${ }^{1}$ Instituto Nacional de

Saúde da Mulher, da

Criança e do Adolescente

Fernandes Figueira,

Fiocruz. Av. Rui Barbosa

716, Flamengo. 22250-020

Rio de Janeiro RJ Brasil.

mariaamendesgomes@

gmail.com

${ }^{2}$ Escola Nacional de Saúde

Pública Sérgio Arouca,

Fiocruz. Rio de Janeiro RJ

Brasil.

${ }^{3}$ Organização Pan-

Americana da Saúde,

Organização Mundial da

Saúde. Brasília DF Brasil.

${ }^{4}$ Departamento de

Medicina III, Universidade

Federal do Maranhão

(UFMA). São Luís MA

Brasil.

${ }^{5}$ Departamento de Saúde

Pública, UFMA. São Luís

MA Brasil.

\begin{abstract}
This paper aims to compare best practices for healthy newborns in public and mixed hospitals affiliated with SUS, according to type of birth, between "Nascer no Brasil/2011" (NB Birth in Brazil) and in the last assessment cycle of Rede Cegonha, here called "Avaliação da Rede Cegonha/2017" (ARC - Stork Network Assessment). NB included a sample with national representativeness of 266 hospitals, and ARC was conducted in 606 maternity hospitals included in the Rede Cegonha strategy, totaling 15,994 and 8,047 pairs of healthy mothers and newborns, respectively.Between the two studies, NB-2011 and ARC-2017, although the proportion of cesarean sections remained around $44 \%$, the prevalence of skin-to -skin contact with newborns, breastfeeding in the delivery room and breastfeeding in the first $24 \mathrm{~h}$ of life increased by $140 \%, 82 \%$ and 6\%, respectively. The proportion of upper airway aspiration of newborns dropped $65 \%$. The results indicate that the use of evidence-based guidelines for the care of healthy newborns has increased in clinical practice, considering the six-year period between the compared studies. Despite the progress, important challenges remain to ensure best practices for all women and newborns, especially in relation to cesarean births.
\end{abstract}

Key words Unified Health System, Stork $\mathrm{Ne}$ twork, Newborn, Birth assistance, Child care
Resumo O artigo tem como objetivo comparar práticas do cuidado ao recém-nascido saudável no momento do nascimento em hospitais públicos e mistos conveniados ao SUS, segundo o tipo de parto, verificadas na pesquisa "Nascer no Brasil/2011" (NB) e no último ciclo avaliativo da $R C$, aqui denominada "Avaliação da Rede Cegonha/2017" (ARC). O NB incluiu uma amostra com representatividade nacional de 266 hospitais e a ARC foi conduzida em 606 maternidades inseridas na estratégia Rede Cegonha, totalizando 15.994 e 8.047 pares de puérperas e recém-nascidos saudáveis, respectivamente. Entre os dois estudos, NB-2011 e ARC-2017, embora a proporção de cesariana tenha se mantido em torno de $44 \%$, a prevalência do contato pele a pele com o $R N$, da amamentação na sala de parto e nas primeiras $24 \mathrm{~h}$ de vida aumentaram, $140 \%, 82 \%$ e 6\%, respectivamente. Já a proporção de aspiração de vias aéreas superiores do $R N$, caiu $65 \%$. Os resultados indicam que o uso de diretrizes baseadas em evidências para o cuidado de recém-nascidos saudáveis aumentou na prática clínica, considerando o periodo de seis anos entre os estudos comparados. Apesar desse progresso, permanecem importantes desafios para garantir as melhores práticas para a totalidade de mulheres e recém-nascidos, principalmente em relação aos partos cesáreos.

Palavras-chaves Sistema Único de Saúde, Rede Cegonha, Recém-nascido, Assistência ao nascimento, Cuidado da criança 


\section{Introdução}

Dados coletados entre 2011 e 2012 pela Pesquisa Nascer no Brasil sobre o padrão de atendimento ao recém-nascido $(\mathrm{RN})$ saudável no momento do nascimento em todo o país evidenciaram práticas ainda distantes do preconizado em maternidades brasileiras. Práticas consideradas inadequadas como uso de oxigênio inalatório $(9,5 \%)$, aspiração de vias aéreas $(71,1 \%)$ e gástrica $(39,7 \%)$ e uso de incubadora $(8,8 \%)$ foram excessivamente usadas. A amamentação no momento do nascimento foi considerada baixa $(16,1 \%)$, mesmo nos hospitais com título de Hospital Amigo da Criança (HAC) $(24 \%)^{1}$. Outros estudos também identificaram a ausência de fatores individuais maternos que pudessem explicar os baixos índices de amamentação na primeira hora ${ }^{2,3}$.

Ao longo das últimas décadas esforços visando à redução dessas intervenções, a promoção do contato pele a pele e a oferta do seio materno no momento do nascimento e o aleitamento nas primeiras 24 horas, práticas reconhecidas pelo seu impacto positivo na saúde infantil ${ }^{4}$ tem sido priorizados nas políticas públicas de saúde através de ações como a Iniciativa Hospital Amigo da Criança (IHAC) e a Atenção Humanizada ao Recém-Nascido de Baixo Peso - Método Canguru. Essas ações foram intensificadas com a implantação de Rede Cegonha (RC) $)^{5,6}$, lançada em 2011 pelo Ministério da Saúde (MS) com foco na melhoria da qualidade da atenção ao parto na rede pública de saúde. As ações de promoção de práticas clínicas humanizadas e baseadas em evidências na atenção ao parto, nascimento e ao $\mathrm{RN}$, envolvendo mais de 600 maternidades públicas ou conveniadas ao SUS, foram elementos centrais no processo de implantação da $\mathrm{RC}^{7}$.

Nesse mesmo período, foram desenvolvidas e/ou intensificadas outras iniciativas de qualificação do cuidado neonatal no momento do nascimento, com destaque para a disseminação de diretrizes clínicas em relação ao cuidado apropriado para $\mathrm{RN}$ com idade gestacional maior ou igual a 34 semanas no momento do nascimento através do Programa Nacional de Reanimação ${ }^{8,9}$. Atualmente as diretrizes internacionais preconizam a não realização de intervenções desnecessárias como aspiração de vias aéreas e gástricas e uso de oxigênio sem indicação $0^{10-12}$.

O monitoramento e a avaliação de práticas na atenção ao parto e nascimento são ferramentas consolidadas no planejamento e gestão de políticas públicas em países com melhor desempenho nos resultados perinatais ${ }^{13-16}$ e foram incluídos como eixos estratégicos da RC através de seus ciclos avaliativos ${ }^{17,18}$.

O objetivo deste artigo é comparar quatro práticas do cuidado ao RN saudável no momento do nascimento em hospitais públicos e privados conveniados ao SUS, segundo o tipo de parto, verificadas na pesquisa "Nascer no Brasil/2011" $(\mathrm{NB})^{19}$ e no último ciclo avaliativo da RC, aqui denominada "Avaliação da Rede Cegonha/2017" (ARC): aspiração de vias aéreas superiores, contato pele a pele, amamentação na primeira hora de vida e amamentação nas primeiras 24 horas de vida.

\section{Métodos}

Neste artigo serão analisados dados de dois estudos nacionais: o Nascer no Brasil (NB), ocorrido em 2011, e a Avaliação da Rede Cegonha (ARC), ocorrida em 2017.

\section{Nascer no Brasil}

Estudo nacional sobre a assistência ao parto e nascimento em uma amostra de 266 hospitais e um total de 23.894 puérperas. A amostra foi selecionada em três estágios. O primeiro foi composto por hospitais com 500 ou mais partos/ano em 2007 (os quais recebem $87 \%$ dos nascimentos do Brasil), estratificado pelas cinco macrorregiões, localização (capital ou não capital) e por tipo de hospital (público, misto e privado). Em cada estrato os hospitais foram selecionados com probabilidade proporcional ao número de partos/ano. No segundo estágio, um método de amostragem inversa foi utilizado para selecionar o número de dias necessários para alcançar 90 puérperas em cada hospital. O terceiro estágio foi composto pelas puérperas elegíveis. Pesos amostrais foram estabelecidos pelo inverso da probabilidade da inclusão de cada puérpera na amostragem. Um procedimento de calibragem foi usado para garantir que a distribuição das puérperas amostradas fosse semelhante àquela observada na população no ano de 2011. Mais detalhes do método utilizado pelo estudo NB foram publicados por Leal e Gama ${ }^{19}$.

\section{Avaliação da Rede Cegonha}

Foram incluídos todos os hospitais públicos e privados conveniados ao SUS (mistos) que, em 2015, eram localizados em região de saúde com plano de ação da RC, totalizando 606 estabele- 
cimentos distribuídos em todos os estados do Brasil.

Foram utilizados três métodos de coleta de dados: 1 - entrevista pessoal com informanteschave: gestores; profissionais de saúde e puérperas; 2 - análise documental, verificou a disponibilidade de normas, protocolos e de indicadores de processo e resultados da assistência ao parto e nascimento foi verificada de forma direta. Dados sobre o cuidado hospitalar foram extraídos do prontuário da mulher e do RN; e 3 - observação in loco que teve por finalidade verificar as condições de infraestrutura e planta física. A avaliação englobou todos os ambientes da maternidade, desde a porta de entrada e recepção até o alojamento conjunto (ALCON), incluindo a unidade neonatal. Para a presente análise, são utilizadas somente as informações coletadas nas entrevistas com as puérperas e os gestores e da análise documental dos prontuários hospitalares.

Com relação à amostra de puérperas, o tamanho mínimo estabelecido para cada macrorregião foi de 1.800 puérperas. Um número fixo de dias de coleta de dados com as mesmas foi definido de acordo com número de nascidos vivos em 2015, em cada macrorregião: dois dias nas regiões Sudeste e Nordeste, quatro dias na região Norte, cinco dias na região Sul e sete dias na região Centro-Oeste. Ao final foram incluídas 10.665 puérperas. Pesos amostrais foram calculados pelo inverso da probabilidade da inclusão de cada puérpera. Um procedimento de calibragem foi usado para garantir que a distribuição das puérperas amostradas correspondesse à distribuição de partos ocorridos nesses 606 hospitais no ano de 2017.

Para os gestores das maternidades, coordenadores/chefes - médico e enfermeiro da Obstetrícia e da Neonatologia, a entrevista foi coletiva. Ao todo foram 2.765 entrevistados. Mais informações sobre o método encontram-se em Vilela et al. ${ }^{18}$.

\section{Critérios de inclusão e exclusão}

Em ambas as pesquisas foram incluídas as puérperas que tiveram parto hospitalar de um nascido vivo, independentemente da idade gestacional e peso, ou um nascido morto com mais de $500 \mathrm{~g}$ ou idade gestacional maior ou igual a 22 semanas. Foram excluídas as mulheres com dificuldades de comunicação (transtorno mental grave, estrangeiras que não entendiam a língua portuguesa e as com deficiência auditiva) e as mulheres com interrupção legal da gravidez. As puérperas foram entrevistadas face a face durante a internação hospitalar e os dados clínicos foram coletados de prontuários hospitalares. Foram utilizados formulários eletrônicos desenvolvidos especificamente para cada estudo.

Para a presente análise, foram excluídos, primeiramente, os nascimentos em hospitais privados do estudo NB (3.539), restando 20.355 puérperas $(85 \%)$ com partos em hospitais públicos ou mistos. Posteriormente, foram suprimidos do NB e da ARC, respectivamente: partos múltiplos (212 e 122), óbitos fetais ou neonatais (267 e 109), RN com Apgar menor que 7 (1.013 e 603), RN que foram internados em unidade de terapia intensiva neonatal (696 e 605), os com menos de 37 semanas gestacionais (1.339 e 666), os nascidos com menos que $2.500 \mathrm{~g}$ (466 e 147) e os sem alguma dessas informações (363 e 366). Após todas as exclusões, foram analisados 15.994 e 8.047 pares de puérperas e $\mathrm{RN}$, correspondentes a $78,6 \%$ da amostra dos hospitais públicos e mistos do estudo NB e a $75,5 \%$ da amostra total da ARC.

\section{Variáveis de exposição}

As variáveis hospitalares incluídas foram: região (Norte, Nordeste, Sudeste, Sul, Centro-oeste), tipo (público, misto), localização (capital, não capital), tamanho (até 999, 1000- 2999, $\geq$ 3000 partos/ano), ser maternidade com o título da IHAC ( sim, não), hospital com atuação de enfermeira obstétrica na atenção ao parto vaginal de risco habitual (sim, não) e disponibilidade de pelo menos um quarto para atenção ao pré-parto, parto e pós-parto imediato (quartos PPP), esta última verificada apenas no estudo da ARC. Todas foram coletadas na entrevista com o gestor.

As variáveis “atuação de enfermeira obstétrica na atenção ao parto vaginal de risco habitual" e "disponibilidade de pelo menos um quarto PPP" foram coletadas no nível hospitalar e não individual. Além disso, foram consideradas como existentes ou não, independentemente de serem absolutas ou de coexistirem diferentes espaços para o cuidado à parturiente e ao $\mathrm{RN}$, e da proporção de partos de risco habitual assistidos pela enfermagem obstétrica.

As variáveis maternas incluídas foram: idade ( $\leq 19,20-34, \geq 35)$, cor de pele (branca, preta, parda), nível de escolaridade (fundamental incompleto, fundamental completo, médio completo, superior completo ou mais), paridade (primípara, 1-2 partos, $\geq 3$ partos), vive com companheiro (sim ou não), presença de acompa- 
nhante hospitalar (não ou parcialmente, todo o tempo) e tipo de parto (vaginal, cesariana). Todas foram coletadas na entrevista com a puérpera.

\section{Desfechos}

Os desfechos foram dicotômicos (sim, não). As boas práticas de atenção ao RN incluídas foram: contato pele a pele na sala de parto, amamentação na primeira hora e amamentação nas primeiras $24 \mathrm{~h}$ após o nascimento. A intervenção incluída foi a aspiração das vias aéreas superiores. As variáveis foram coletadas, nos dois estudos, em entrevista com a puérpera, com exceção da aspiração das vias aéreas superiores, extraída do prontuário hospitalar tanto no NB quanto na ARC.

\section{Análise dos dados}

Inicialmente descrevemos as características hospitalares e das mulheres, assim como a prevalência dos desfechos estudados, para ambos os estudos.

Em seguida calculam-se as diferenças absolutas de prevalência e as razões de prevalência dos desfechos entre os dois estudos, de acordo com as variáveis de exposição e estratificando-se pelo tipo de parto, vaginal ou cesariana. Para a avaliação da significância estatística foi utilizado o teste qui-quadrado para amostras independentes e nível de confiança de $95 \%$, utilizando o programa estatístico SPSS versão 22.0

\section{Avaliação ética}

Os estudos Nascer no Brasil e Avaliação da Rede Cegonha pautam-se pela Resolução 196/96 do Conselho Nacional de Saúde do Brasil, que estabelece diretrizes e parâmetros para a pesquisa humana e pela Resolução 466/12, da Comissão Nacional de Ética e Pesquisa que regulamenta as Diretrizes e Normas da Pesquisa em Seres Humanos, do Ministério da Saúde, resguardando os princípios éticos da autonomia, justiça, beneficência e da não maleficência, segundo os protocolos de pesquisa. Tomou-se o cuidado de garantir e preservar a privacidade e a confidencialidade dos dados de pesquisa. Todos os diretores de hospital e puérperas passaram por uma consulta de consentimento prévio e, posteriormente, assinaram um termo de consentimento informado.

\section{Resultados}

Em comparação aos hospitais do NB, os avaliados pela ARC eram mais frequentemente públicos que mistos, com maior volume de partos anual, tiveram maior atuação da enfermagem obstétrica na atenção ao parto e maior proporção de mulheres com acompanhante durante todo o tempo de internação hospitalar. Com relação às características das mulheres, as incluídas na ARC eram mais velhas, com maior nível de escolaridade e se autodeclararam pretas com maior proporção que as do NB. As outras características analisadas foram equiparáveis (Tabela 1).

Entre os dois estudos, NB (2011) e ARC (2017), embora a proporção de cesariana tenha se mantido em torno de 44\%, observou-se aumento na prevalência do contato pele a pele com o RN (de 140\%) e da amamentação na sala de parto (de $82 \%$ ). Já a proporção de aspiração de vias aéreas superiores do $\mathrm{RN}$, intervenção reconhecida como desnecessária, caiu 65\% (Tabela 1).

Nas Tabelas 2 a 5, cada prática do cuidado ao RN saudável foi estratificada segundo o tipo de parto.

O contato pele a pele na sala de parto duplicou para os partos vaginais e triplicou para as cesarianas. No entanto, embora as discrepâncias entre os tipos de parto tenham reduzido, as cesarianas permaneceram com menos da metade da prevalência observada nos partos vaginais. A região Nordeste, que possuía a menor prevalência no $\mathrm{NB}$, foi a que teve o maior aumento dessa boa prática entre os partos vaginais, alcançando o mesmo patamar das outras regiões. Com relação ao hospital ter ou não o título da IHAC, no estudo NB a prevalência do contato pele a pele foi maior nos hospitais com este título - 50\% maior nos partos vaginais e $170 \%$ maior nas cesarianas. Já no estudo ARC observamos uma redução nessas diferenças. Nos dois períodos estudados, o hospital contar com a presença de enfermeira obstetra na atenção ao parto vaginal, assim como a mulher ter tido acompanhante em tempo integral, favoreceram o contato pele a pele. Com relação às características maternas, as mulheres de cor da pele preta, em comparação às brancas e pardas, tiveram um maior aumento do contato pele a pele para os partos vaginais; o que não aconteceu para as cesarianas, em que o aumento foi superior nas mulheres brancas (Tabela 2). 
Tabela 1. Distribuição das características hospitalares e das puérperas e prevalência dos desfechos nos dois estudos.

\begin{tabular}{|c|c|c|c|c|c|c|}
\hline & \multicolumn{3}{|c|}{ Nascer no Brasil } & \multicolumn{3}{|c|}{ Avaliação da Rede Cegonha } \\
\hline & n (15.994) & $\%$ & IC & n (8.047) & $\%$ & IC \\
\hline \multicolumn{7}{|l|}{ Características hospitalares } \\
\hline \multicolumn{7}{|l|}{ Região } \\
\hline Norte & 1.638 & 10,2 & $(6,8-15,1)$ & 1.089 & 13,5 & $(10,5-17,3)$ \\
\hline Nordeste & 4.454 & 27,8 & $(21,4-35,3)$ & 2.456 & 30,5 & $(26,2-35,3)$ \\
\hline Sudeste & 6.874 & 43,0 & $(35,2-51,1)$ & 2.962 & 36,8 & $(32,2-41,7)$ \\
\hline Sul & 2.026 & 12,7 & $(8,9-17,7)$ & 923 & 11,5 & $(9,0-14,5)$ \\
\hline Centro-oeste & 1.002 & 6,3 & $(3,9-9,9)$ & 617 & 7,7 & $(5,2-11,1)$ \\
\hline \multicolumn{7}{|l|}{ Tipo } \\
\hline SUS & 7.416 & 46,4 & $(38,7-54,2)$ & 4.822 & 59,9 & $(55,0-64,3)^{\star}$ \\
\hline Misto & 8.579 & 53,6 & $(45,8-61,3)$ & 3.225 & 40,1 & $(35,4-45,0)$ \\
\hline \multicolumn{7}{|l|}{ Localidade } \\
\hline Não capital & 10.523 & 65,8 & $(57,2-73,5)$ & 4.851 & 60,3 & $(55,2-65,2)$ \\
\hline Capital & 5.471 & 34,2 & $(26,5-42,8)$ & 3.196 & 39,7 & $(34,8-44,8)$ \\
\hline \multicolumn{7}{|l|}{ Volume de Parto } \\
\hline até 999 & 2.049 & 12,8 & $(8,8-18,3)$ & 548 & 6,8 & $(5,6-8,3)^{\star}$ \\
\hline 1000 a 2999 & 7.199 & 45,0 & $(37,6-52,7)$ & 3.206 & 39,8 & $(35,5-44,4)$ \\
\hline$\geq 3000$ & 6.747 & 42,2 & $(34,4-50,4)$ & 4.293 & 53,3 & $(48,6-58,1)$ \\
\hline IHAC & 7.274 & 45,5 & $(37,9-53,3)$ & 2.900 & 36,0 & $(31,3-41,0)$ \\
\hline Enfermeira na atenção ao parto & 7.546 & 47,2 & $(39,4-55,1)$ & 6.108 & 75,9 & $(71,9-79,5)^{*}$ \\
\hline Presença de quartos $\mathrm{PPP}^{\star \star}$ & - & - & - & 1.196 & 14,9 & $(11,4-19,2)$ \\
\hline \multicolumn{7}{|l|}{ Acompanhante hospitalar } \\
\hline Não ou parcialmente & 13.114 & 82,0 & $(77,9-85,5)$ & 2.179 & 27,6 & $(25,8-29,7)$ \\
\hline Todo o tempo & 2.876 & 18,0 & $(14,5-22,1)$ & 5.822 & 72,8 & $(70,3-75,1)^{\star}$ \\
\hline \multicolumn{7}{|l|}{ Características das puérperas } \\
\hline \multicolumn{7}{|l|}{ Idade } \\
\hline 15 a 19 anos & 3.362 & 21,0 & $(19,9-22,2)$ & 1.621 & 20,2 & $(19,1-21,3)$ \\
\hline 20 a 34 anos & 11.279 & 70,5 & $(69,4-71,6)$ & 5.584 & 69,4 & $(68,2-70,6)$ \\
\hline 35 ou mais & 1.352 & 8,5 & $(7,8-9,2)$ & 840 & 10,4 & $(9,7-11,3)^{*}$ \\
\hline \multicolumn{7}{|l|}{ Raça/Cor } \\
\hline Branca & 4.929 & 30,8 & $(27,9-33,9)$ & 2.125 & 26,6 & $(24,7-28,7)$ \\
\hline Preta & 1.512 & 9,5 & $(8,4-10,7)$ & 1.049 & 13,1 & $(12,1-14,3)^{*}$ \\
\hline Parda & 9.551 & 59,7 & $(56,8-62,6)$ & 4.804 & 60,2 & $(58,2-62,2)$ \\
\hline \multicolumn{7}{|l|}{ Escolaridade } \\
\hline EF incompleto & 4.770 & 29,9 & $(27,8-32,2)$ & 875 & 10,9 & $(10,0-11,9)$ \\
\hline EF completo & 4.593 & 28,8 & $(27,6-30,0)$ & 2.104 & 26,2 & $(25,0-27,4)$ \\
\hline EM completo & 5.900 & 37,0 & $(34,9-39,2)$ & 4.531 & 56,5 & $(55,0-57,9)^{\star}$ \\
\hline ES completo e mais & 674 & 4,2 & $(3,6-4,9)$ & 513 & 6,4 & $(5,7-7,2)^{\star}$ \\
\hline Vive com companheiro & 12.800 & 80,1 & $(78,8-81,3)$ & 6.341 & 79,0 & $(77,6-80,4)$ \\
\hline \multicolumn{7}{|l|}{ Paridade } \\
\hline Primípara & 7.043 & 44,0 & $(42,8-45,3)$ & 3.713 & 46,3 & $(44,1-48,5)$ \\
\hline 1-2 partos anteriores & 7.094 & 44,4 & $(43,3-45,4)$ & 3.359 & 41,9 & $(40,0-43,8)$ \\
\hline 3 ou mais partos anteriores & 1.857 & 11,6 & $(10,6-12,8)$ & 947 & 11,8 & $(10,8-12,9)$ \\
\hline \multicolumn{7}{|l|}{ Tipo de parto } \\
\hline Vaginal & 8.921 & 55,8 & $(52,7-58,8)$ & 4.568 & 56,8 & $(55,0-58,5)$ \\
\hline Cesariana & 7.073 & 44,2 & $(41,2-47,3)$ & 3.478 & 43,2 & $(41,5-45,0)$ \\
\hline \multicolumn{7}{|l|}{ Desfechos } \\
\hline Contato pele a pele na sala de parto & 4.554 & 28,5 & $(25,5-31,7)$ & 5.366 & 67,5 & $(65,4-69,5)^{\star}$ \\
\hline Amamentação na sala de parto & 2.710 & 17,0 & $(13,8-20,7)$ & 2.454 & 31,0 & $(28,6-33,5)^{\star}$ \\
\hline Amamentação nas primeiras $24 \mathrm{~h}$ & 14.187 & 91,5 & $(89,9-92,9)$ & 7.676 & 96,6 & $(96,0-97,2)^{\star}$ \\
\hline Aspiração de vias aéreas superiores & 11.427 & 71,4 & $(66,6-75,9)$ & 2.058 & 25,6 & $(23,1-28,3)^{\star}$ \\
\hline
\end{tabular}


Tabela 2. Prevalência do contato pele a pele (\%) e diferenças entre os estudos NB e ARC segundo características hospitalares e maternas, para o parto vaginal e cesariana.

\begin{tabular}{|c|c|c|c|c|c|c|c|c|c|c|}
\hline & \multicolumn{5}{|c|}{ Vaginal } & \multicolumn{5}{|c|}{ Cesariana } \\
\hline & $\begin{array}{c}\text { NB } \\
(\mathbf{n}= \\
8.921)\end{array}$ & $\begin{array}{c}\text { ARC } \\
(n= \\
4.568)\end{array}$ & $\begin{array}{c}\text { Dif. } \\
\text { Absoluta }\end{array}$ & Razão & $\begin{array}{c}\text { P- } \\
\text { valor }^{*}\end{array}$ & $\begin{array}{c}\text { NB } \\
(\mathbf{n}= \\
7.073)\end{array}$ & $\begin{array}{c}\text { ARC } \\
(\mathrm{n}= \\
3.478)\end{array}$ & $\begin{array}{c}\text { Dif. } \\
\text { Absoluta }\end{array}$ & Razão & $\begin{array}{c}\text { P- } \\
\text { valor }^{*}\end{array}$ \\
\hline Total & 41,4 & 87,1 & 45,7 & 2,1 & $<0,001$ & 12,3 & 41,9 & 29,6 & 3,4 & $<0,001$ \\
\hline \multicolumn{11}{|c|}{ Características hospitalares } \\
\hline \multicolumn{11}{|c|}{ Região } \\
\hline Norte & 43,7 & 89,7 & 46,0 & 2,1 & $<0,001$ & 9,0 & 24,0 & 15,0 & 2,7 & 0,002 \\
\hline Nordeste & 37,3 & 88,9 & 51,6 & 2,4 & $<0,001$ & 14,3 & 43,5 & 29,2 & 3,0 & $<0,001$ \\
\hline Sudeste & 40,9 & 83,0 & 42,1 & 2,0 & $<0,001$ & 11,2 & 43,0 & 31,8 & 3,8 & $<0,001$ \\
\hline Sul & 51,3 & 90,8 & 39,5 & 1,8 & $<0,001$ & 14,3 & 52,3 & 38,0 & 3,7 & $<0,001$ \\
\hline Centro-oeste & 40,8 & 90,0 & 49,2 & 2,2 & $<0,001$ & 12,8 & 49,8 & 37,0 & 3,9 & $<0,001$ \\
\hline \multicolumn{11}{|l|}{ Tipo } \\
\hline SUS & 41,7 & 87,9 & 46,2 & 2,1 & $<0,001$ & 14,9 & 41,8 & 26,9 & 2,8 & $<0,001$ \\
\hline Misto & 41,0 & 85,5 & 44,5 & 2,1 & $<0,001$ & 10,7 & 42,0 & 31,3 & 3,9 & $<0,001$ \\
\hline \multicolumn{11}{|l|}{ Localidade } \\
\hline Não capital & 37,5 & 84,9 & 47,4 & 2,3 & $<0,001$ & 11,0 & 37,1 & 26,1 & 3,4 & $<0,001$ \\
\hline Capital & 48,0 & 90,2 & 42,2 & 1,9 & $<0,001$ & 15,3 & 49,7 & 34,4 & 3,2 & $<0,001$ \\
\hline \multicolumn{11}{|l|}{ Volume de Parto } \\
\hline até 999 & 36,6 & 79,9 & 43,3 & 2,2 & $<0,001$ & 11,5 & 34,9 & 23,4 & 3,0 & $<0,001$ \\
\hline 1000 a 2999 & 38,1 & 83,5 & 45,4 & 2,2 & $<0,001$ & 10,3 & 37,6 & 27,3 & 3,7 & $<0,001$ \\
\hline$\geq 3000$ & 45,3 & 90,2 & 44,9 & 2,0 & $<0,001$ & 15,6 & 46,7 & 31,1 & 3,0 & $<0,001$ \\
\hline \multicolumn{11}{|l|}{ IHAC } \\
\hline Não & 33,0 & 84,5 & 51,5 & 2,6 & $<0,001$ & 7,5 & 38,6 & 31,1 & 5,1 & $<0,001$ \\
\hline Sim & 50,1 & 91,2 & 41,1 & 1,8 & $<0,001$ & 19,2 & 48,3 & 29,1 & 2,5 & $<0,001$ \\
\hline \multicolumn{11}{|l|}{$\begin{array}{l}\text { Enfermeira obstétrica } \\
\text { na atenção ao parto }\end{array}$} \\
\hline Não & 34,9 & 80,7 & 45,8 & 2,3 & $<0,001$ & 10,7 & 42,6 & 31,9 & 4,0 & $<0,001$ \\
\hline Sim & 48,1 & 88,8 & 40,7 & 1,8 & $<0,001$ & 14,3 & 41,6 & 27,3 & 2,9 & $<0,001$ \\
\hline \multicolumn{11}{|l|}{$\begin{array}{l}\text { Presença de quartos } \\
\text { PPP }^{\star \star}\end{array}$} \\
\hline Não & - & 86,0 & - & - & - & - & 42,0 & - & - & - \\
\hline Sim & - & 92,2 & - & - & - & - & 41,5 & - & - & - \\
\hline \multicolumn{11}{|l|}{$\begin{array}{l}\text { Acompanhante } \\
\text { hospitalar }\end{array}$} \\
\hline Não ou parcialmente & 37,4 & 78,5 & 41,1 & 2,1 & $<0,001$ & 10,3 & 31,6 & 21,3 & 3,1 & $<0,001$ \\
\hline Todo o tempo & 56,2 & 89,5 & 33,3 & 1,6 & $<0,001$ & 24,9 & 47,2 & 22,3 & 1,9 & $<0,001$ \\
\hline \multicolumn{11}{|c|}{ Características das puérperas } \\
\hline \multicolumn{11}{|c|}{ Idade } \\
\hline$\leq 19$ anos & 39,0 & 86,3 & 47,3 & 2,2 & $<0,001$ & 9,4 & 35,7 & 26,3 & 3,8 & $<0,001$ \\
\hline 20 a 34 anos & 42,3 & 87,4 & 45,1 & 2,1 & $<0,001$ & 12,1 & 42,3 & 30,2 & 3,5 & $<0,001$ \\
\hline 35 ou mais & 40,4 & 86,3 & 45,9 & 2,1 & $<0,001$ & 18,2 & 47,3 & 29,1 & 2,6 & $<0,001$ \\
\hline \multicolumn{11}{|l|}{ Raça/Cor } \\
\hline Branca & 43,3 & 85,6 & 42,3 & 2,0 & $<0,001$ & 12,8 & 45,2 & 32,4 & 3,5 & $<0,001$ \\
\hline Preta & 36,2 & 89,9 & 53,7 & 2,5 & $<0,001$ & 13,3 & 41,7 & 28,4 & 3,1 & $<0,001$ \\
\hline Parda & 41,4 & 87,3 & 45,9 & 2,1 & $<0,001$ & 11,9 & 40,2 & 28,3 & 3,4 & $<0,001$ \\
\hline \multicolumn{11}{|l|}{ Escolaridade } \\
\hline EF incompleto & 40,8 & 83,2 & 42,4 & 2,0 & $<0,001$ & 12,6 & 45,1 & 32,5 & 3,6 & $<0,001$ \\
\hline EF completo & 41,3 & 87,1 & 45,8 & 2,1 & $<0,001$ & 10,3 & 38,6 & 28,3 & 3,7 & $<0,001$ \\
\hline EM completo & 41,6 & 87,7 & 46,1 & 2,1 & $<0,001$ & 12,7 & 41,7 & 29,0 & 3,3 & $<0,001$ \\
\hline ES completo e mais & 47,3 & 89,8 & 42,5 & 1,9 & $<0,001$ & 16,2 & 49,6 & 33,4 & 3,1 & $<0,001$ \\
\hline
\end{tabular}


Tabela 2. Prevalência do contato pele a pele (\%) e diferenças entre os estudos NB e ARC segundo características hospitalares e maternas, para o parto vaginal e cesariana.

\begin{tabular}{|c|c|c|c|c|c|c|c|c|c|c|}
\hline & \multicolumn{5}{|c|}{ Vaginal } & \multicolumn{5}{|c|}{ Cesariana } \\
\hline & $\begin{array}{c}\text { NB } \\
(\mathbf{n}= \\
\mathbf{8 . 9 2 1})\end{array}$ & $\begin{array}{c}\begin{array}{c}\text { ARC } \\
(n=\end{array} \\
4.568)\end{array}$ & $\begin{array}{c}\text { Dif. } \\
\text { Absoluta }\end{array}$ & Razão & $\begin{array}{c}\text { P- } \\
\text { valor }^{*}\end{array}$ & $\begin{array}{c}\text { NB } \\
(\mathbf{n}= \\
7.073)\end{array}$ & $\begin{array}{c}\text { ARC } \\
(\mathrm{n}= \\
3.478)\end{array}$ & $\begin{array}{c}\text { Dif. } \\
\text { Absoluta }\end{array}$ & Razão & $\begin{array}{c}\text { P- } \\
\text { valor }^{*}\end{array}$ \\
\hline \multicolumn{11}{|l|}{ Vive com companheiro } \\
\hline Não & 42,4 & 85,0 & 42,6 & 2,0 & $<0,001$ & 10,3 & 36,8 & 26,5 & 3,6 & $<0,001$ \\
\hline Sim & 41,1 & 87,6 & 46,5 & 2,1 & $<0,001$ & 12,6 & 43,1 & 30,5 & 3,4 & $<0,001$ \\
\hline \multicolumn{11}{|l|}{ Paridade } \\
\hline Primípara & 42,0 & 87,2 & 45,2 & 2,1 & $<0,001$ & 11,4 & 42,5 & 31,1 & 3,7 & $<0,001$ \\
\hline 1-2 partos anteriores & 41,4 & 87,2 & 45,8 & 2,1 & $<0,001$ & 13,8 & 41,7 & 27,9 & 3,0 & $<0,001$ \\
\hline $\begin{array}{l}3 \text { ou mais partos } \\
\text { anteriores }\end{array}$ & 39,3 & 86,1 & 46,8 & 2,2 & $<0,001$ & 9,5 & 40,5 & 31,0 & 4,2 & $<0,001$ \\
\hline
\end{tabular}

Tabela 3. Prevalência da amamentação na sala de parto (\%) e diferenças entre os estudos NB e ARC segundo características hospitalares e maternas, para o parto vaginal e cesariana.

\begin{tabular}{|c|c|c|c|c|c|c|c|c|c|c|}
\hline & \multicolumn{5}{|c|}{ Vaginal } & \multicolumn{5}{|c|}{ Cesariana } \\
\hline & $\begin{array}{c}\text { NB } \\
(\mathbf{n}= \\
8.921)\end{array}$ & $\begin{array}{c}\text { ARC } \\
(\mathrm{n}= \\
\mathbf{4 . 5 6 8})\end{array}$ & $\begin{array}{l}\text { Dif. } \\
\text { Absoluta }\end{array}$ & Razão & $\begin{array}{c}\text { P- } \\
\text { valor }^{*}\end{array}$ & $\begin{array}{c}\text { NB } \\
(\mathrm{n}= \\
7.073)\end{array}$ & $\begin{array}{c}\text { ARC } \\
(\mathrm{n}= \\
3.478)\end{array}$ & $\begin{array}{c}\text { Dif. } \\
\text { Absoluta }\end{array}$ & Razão & $\begin{array}{c}\text { P- } \\
\text { valor }^{\star}\end{array}$ \\
\hline Total & 22,5 & 44,1 & 21,6 & 2,0 & $<0,001$ & 10,0 & 13,9 & 3,9 & 1,4 & 0,015 \\
\hline \multicolumn{11}{|c|}{ Características hospitalares } \\
\hline \multicolumn{11}{|c|}{ Região } \\
\hline Norte & 17,5 & 44,9 & 27,4 & 2,6 & 0,001 & 5,6 & 11,7 & 6,1 & 2,1 & 0,019 \\
\hline Nordeste & 16,0 & 36,3 & 20,3 & 2,3 & $<0,001$ & 6,7 & 10,3 & 3,6 & 1,5 & 0,131 \\
\hline Sudeste & 26,5 & 46,9 & 20,4 & 1,8 & 0,001 & 10,2 & 17,3 & 7,1 & 1,7 & 0,011 \\
\hline Sul & 30,9 & 48,5 & 17,6 & 1,6 & 0,003 & 17,4 & 16,5 & $-0,9$ & 0,9 & 0,867 \\
\hline Centro-oeste & 17,5 & 51,1 & 33,6 & 2,9 & 0,001 & 12,3 & 13,9 & 1,6 & 1,1 & 0,761 \\
\hline \multicolumn{11}{|l|}{ Tipo } \\
\hline SUS & 23,2 & 45,7 & 22,5 & 2,0 & $<0,001$ & 13,1 & 15,5 & 2,4 & 1,2 & 0,348 \\
\hline Misto & 21,7 & 41,2 & 19,5 & 1,9 & 0,001 & 8,1 & 11,8 & 3,7 & 1,5 & 0,071 \\
\hline \multicolumn{11}{|l|}{ Localidade } \\
\hline Não capital & 18,2 & 37,3 & 19,1 & 2,0 & $<0,001$ & 10,0 & 12,0 & 2,0 & 1,2 & 0,320 \\
\hline Capital & 29,8 & 53,6 & 23,8 & 1,8 & $<0,001$ & 9,9 & 17,0 & 7,1 & 1,7 & 0,005 \\
\hline \multicolumn{11}{|l|}{ Volume de Parto } \\
\hline até 999 & 9,8 & 28,4 & 18,6 & 2,9 & $<0,001$ & 7,8 & 12,1 & 4,3 & 1,6 & 0,324 \\
\hline 1000 a 2999 & 18,9 & 41,7 & 22,8 & 2,2 & $<0,001$ & 10,7 & 12,6 & 1,9 & 1,2 & 0,458 \\
\hline$\geq 3000$ & 28,5 & 47,3 & 18,8 & 1,7 & $<0,001$ & 9,9 & 15,3 & 5,4 & 1,6 & 0,011 \\
\hline \multicolumn{11}{|l|}{ IHAC } \\
\hline Não & 16,6 & 40,9 & 24,3 & 2,5 & $<0,001$ & 5,8 & 12,3 & 6,5 & 2,1 & 0,001 \\
\hline Sim & 28,7 & 49,1 & 20,4 & 1,7 & $<0,001$ & 15,9 & 17,1 & 1,2 & 1,1 & 0,653 \\
\hline \multicolumn{11}{|c|}{$\begin{array}{l}\text { Enfermeira na atenção } \\
\text { ao parto }\end{array}$} \\
\hline Não & 13,2 & 37,0 & 23,8 & 2,8 & $<0,001$ & 7,6 & 14,1 & 6,5 & 1,9 & 0,006 \\
\hline Sim & 32,3 & 45,9 & 13,6 & 1,4 & 0,003 & 12,9 & 13,8 & 0,9 & 1,1 & 0,683 \\
\hline
\end{tabular}




\begin{tabular}{|c|c|c|c|c|c|c|c|c|c|c|c|}
\hline \multirow{3}{*}{\multicolumn{2}{|c|}{$\begin{array}{l}\text { abela 3. Prevalência da } \\
\text { aracterísticas hospitala }\end{array}$}} & $\begin{array}{l}\text { amamen } \\
\text { es e mate }\end{array}$ & $\begin{array}{l}\text { ção na s } \\
\text { nas, para }\end{array}$ & $\begin{array}{l}\text { Ala de parto } \\
\text { o parto vag }\end{array}$ & $\begin{array}{l}(\%) \text { e di } \\
\text { inal e ce }\end{array}$ & $\begin{array}{l}\text { iferenças } \\
\text { esariana. }\end{array}$ & ntre os e & tudos $\mathrm{N}$ & B e ARC seg & indo & \\
\hline & & \multicolumn{5}{|c|}{ Vaginal } & \multicolumn{5}{|c|}{ Cesariana } \\
\hline & & $\begin{array}{c}\text { NB } \\
(\mathbf{n}= \\
8.921)\end{array}$ & $\begin{array}{c}\text { ARC } \\
(n= \\
4.568)\end{array}$ & $\begin{array}{c}\text { Dif. } \\
\text { Absoluta }\end{array}$ & Razão & $\begin{array}{c}\text { P- } \\
\text { valor }^{\star}\end{array}$ & $\begin{array}{c}\text { NB } \\
(\mathbf{n}= \\
7.073)\end{array}$ & $\begin{array}{c}\text { ARC } \\
(\mathbf{n}= \\
3.478)\end{array}$ & $\begin{array}{c}\text { Dif. } \\
\text { Absoluta }\end{array}$ & Razão & $\begin{array}{c}\text { P- } \\
\text { valor }^{*}\end{array}$ \\
\hline & \multicolumn{11}{|l|}{$\begin{array}{l}\text { Presença de quartos } \\
\operatorname{PPP}^{\star *}\end{array}$} \\
\hline & Não & - & 39,3 & - & - & - & - & 13,8 & - & - & - \\
\hline & Sim & - & 67,2 & - & - & - & - & 14,9 & - & - & - \\
\hline & \multicolumn{11}{|l|}{$\begin{array}{l}\text { Acompanhante } \\
\text { hospitalar }\end{array}$} \\
\hline & Não ou parcialmente & 17,8 & 29,9 & 12,1 & 1,7 & $<0,001$ & 8,4 & 8,8 & 0,4 & 1,1 & 0,759 \\
\hline & Todo o tempo & 39,8 & 48,1 & 8,3 & 1,2 & 0,039 & 20,1 & 16,6 & $-3,5$ & 0,8 & 0,258 \\
\hline & \multicolumn{11}{|c|}{ Características das puérperas } \\
\hline & \multicolumn{11}{|c|}{ Idade } \\
\hline & $\leq 19$ anos & 20,5 & 39,4 & 18,9 & 1,9 & $<0,001$ & 8,3 & 9,1 & 0,8 & 1,1 & 0,662 \\
\hline & 20 a 34 anos & 23,2 & 45,3 & 22,1 & 1,9 & $<0,001$ & 10,2 & 13,9 & 3,7 & 1,4 & 0,032 \\
\hline & 35 ou mais & 22,4 & 46,1 & 23,7 & 2,1 & $<0,001$ & 11,4 & 19,3 & 7,9 & 1,7 & 0,016 \\
\hline & \multicolumn{11}{|l|}{ Raça/Cor } \\
\hline & Branca & 26,2 & 43,9 & 17,7 & 1,7 & $<0,001$ & 11,7 & 18,3 & 6,6 & 1,6 & 0,022 \\
\hline & Preta & 22,7 & 49,3 & 26,6 & 2,2 & $<0,001$ & 11,0 & 12,3 & 1,3 & 1,1 & 0,701 \\
\hline & Parda & 20,9 & 43,1 & 22,2 & 2,1 & $<0,001$ & 8,7 & 12,3 & 3,6 & 1,4 & 0,012 \\
\hline & \multicolumn{11}{|l|}{ Escolaridade } \\
\hline & EF incompleto & 20,1 & 40,4 & 20,3 & 2,0 & $<0,001$ & 8,8 & 13,5 & 4,7 & 1,5 & 0,086 \\
\hline & EF completo & 22,5 & 40,3 & 17,8 & 1,8 & $<0,001$ & 9,4 & 14,0 & 4,6 & 1,5 & 0,024 \\
\hline & EM completo & 25,2 & 45,8 & 20,6 & 1,8 & $<0,001$ & 10,9 & 12,9 & 2,0 & 1,2 & 0,288 \\
\hline & ES completo e mais & 21,9 & 53,6 & 31,7 & 2,4 & $<0,001$ & 10,8 & 21,2 & 10,4 & 2,0 & 0,010 \\
\hline & \multicolumn{11}{|l|}{ Vive com companheiro } \\
\hline & Não & 21,3 & 43,5 & 22,2 & 2,0 & $<0,001$ & 8,9 & 13,2 & 4,3 & 1,5 & 0,084 \\
\hline & Sim & 22,8 & 44,1 & 21,3 & 1,9 & $<0,001$ & 10,2 & 14,1 & 3,9 & 1,4 & 0,017 \\
\hline & \multicolumn{11}{|l|}{ Paridade } \\
\hline & Primípara & 22,1 & 44,0 & 21,9 & 2,0 & $<0,001$ & 9,5 & 13,5 & 4,0 & 1,4 & 0,040 \\
\hline & 1-2 partos anteriores & 23,2 & 43,7 & 20,5 & 1,9 & $<0,001$ & 10,7 & 14,2 & 3,5 & 1,3 & 0,044 \\
\hline & $\begin{array}{l}3 \text { ou mais partos } \\
\text { anteriores }\end{array}$ & 21,4 & 45,6 & 24,2 & 2,1 & $<0,001$ & 8,9 & 14,0 & 5,1 & 1,6 & 0,060 \\
\hline
\end{tabular}

${ }^{\star}$ P-valor $<0,05$ no teste chi-quadrado de Pearson. ${ }^{* \star}$ Quartos com cama PPP: pré-parto, parto e pós-parto.

A amamentação na primeira hora de vida foi mais frequente entre os RN de parto vaginal, em ambos os estudos. Durante o período, a prática duplicou para os partos vaginais e subiu em 30\% entre as cesarianas, aumentando, portanto, as discrepâncias entre os tipos de parto. As maiores prevalências de amamentação na sala de parto foram constatadas nos hospitais públicos, localizados na capital e com mais de 3.000 partos/ano, em hospitais com iniciativa IHAC e que contam com a presença da enfermeira na atenção ao parto. Entretanto, essa boa prática teve um crescimento maior entre os hospitais não IHAC e sem atuação da enfermagem obstétrica na atenção ao parto. No estudo da ARC, foi maior a amamentação na primeira hora de vida (nos partos vaginais) quando quartos PPP estavam presentes no hospital. Com relação às características das mulheres, as com ensino superior completo tiveram um aumento mais expressivo da amamentação na primeira hora de vida, independentemente do tipo de parto. Por outro lado, as mulheres de cor da pele preta tiveram um maior aumento desta prática entre os partos vaginais, e as mulheres brancas e com $\geq 35$ anos, um maior aumento desta prática nas cesarianas (Tabela 3 ). 
Tabela 4. Prevalência de amamentação nas primeiras 24 horas de vida (\%) e diferenças entre os estudos NB e ARC segundo características hospitalares e maternas, para o parto vaginal e cesariana.

\begin{tabular}{|c|c|c|c|c|c|c|c|c|c|c|}
\hline & \multicolumn{5}{|c|}{ Vaginal } & \multicolumn{5}{|c|}{ Cesariana } \\
\hline & $\begin{array}{c}\text { NB } \\
(\mathbf{n}= \\
\mathbf{8 . 9 2 1 )}\end{array}$ & $\begin{array}{c}\text { ARC } \\
(n= \\
4.568)\end{array}$ & $\begin{array}{l}\text { Dif. } \\
\text { Absoluta }\end{array}$ & Razão & $\begin{array}{c}\text { P- } \\
\text { valor }^{\star}\end{array}$ & $\begin{array}{c}\text { NB } \\
(\mathbf{n}= \\
7.073)\end{array}$ & $\begin{array}{c}\begin{array}{c}\text { ARC } \\
(n=\end{array} \\
3.478)\end{array}$ & $\begin{array}{c}\text { Dif. } \\
\text { Absoluta }\end{array}$ & Razão & $\begin{array}{c}\text { P- } \\
\text { valor }^{*}\end{array}$ \\
\hline Total & 93,7 & 97,8 & 4,1 & 1,04 & $<0,001$ & 88,7 & 95,1 & 6,4 & 1,07 & $<0,001$ \\
\hline \multicolumn{11}{|c|}{ Características hospitalares } \\
\hline \multicolumn{11}{|l|}{ Região } \\
\hline Norte & 97,0 & 98,8 & 1,8 & 1,02 & 0,057 & 92,1 & 95,5 & 3,4 & 1,04 & 0,071 \\
\hline Nordeste & 91,5 & 97,8 & 6,3 & 1,07 & $<0,001$ & 85,7 & 96,3 & 10,6 & 1,12 & $<0,001$ \\
\hline Sudeste & 93,4 & 97,3 & 3,9 & 1,04 & 0,003 & 87,7 & 93,8 & 6,1 & 1,07 & $<0,001$ \\
\hline Sul & 96,2 & 98,5 & 2,3 & 1,02 & 0,009 & 91,6 & 94,8 & 3,2 & 1,04 & 0,268 \\
\hline Centro-oeste & 96,4 & 97,4 & 1,0 & 1,01 & 0,233 & 94,8 & 95,7 & 0,9 & 1,01 & 0,506 \\
\hline \multicolumn{11}{|l|}{ Tipo } \\
\hline SUS & 94,8 & 97,7 & 2,9 & 1,03 & $<0,001$ & 88,7 & 95,4 & 6,7 & 1,08 & $<0,001$ \\
\hline Misto & 92,5 & 97,9 & 5,4 & 1,06 & $<0,001$ & 88,7 & 94,8 & 6,1 & 1,07 & $<0,001$ \\
\hline \multicolumn{11}{|l|}{ Localidade } \\
\hline Não capital & 93,4 & 98,1 & 4,7 & 1,05 & $<0,001$ & 88,5 & 94,5 & 6,0 & 1,07 & $<0,001$ \\
\hline Capital & 94,3 & 97,4 & 3,1 & 1,03 & 0,026 & 88,9 & 96,1 & 7,2 & 1,08 & $<0,001$ \\
\hline \multicolumn{11}{|l|}{ Volume de Parto } \\
\hline até 999 & 94,8 & 98,6 & 3,8 & 1,04 & 0,011 & 90,7 & 94,0 & 3,3 & 1,04 & 0,110 \\
\hline 1000 a 2999 & 93,3 & 98,1 & 4,8 & 1,05 & $<0,001$ & 89,3 & 95,5 & 6,2 & 1,07 & $<0,001$ \\
\hline$\geq 3000$ & 93,8 & 97,5 & 3,7 & 1,04 & 0,001 & 86,8 & 95,0 & 8,2 & 1,09 & $<0,001$ \\
\hline \multicolumn{11}{|l|}{ IHAC } \\
\hline Não & 93,2 & 97,5 & 4,3 & 1,05 & $<0,001$ & 88,4 & 94,1 & 5,7 & 1,06 & $<0,001$ \\
\hline Sim & 94,3 & 98,3 & 4,0 & 1,04 & $<0,001$ & 89,0 & 97,0 & 8,0 & 1,09 & $<0,001$ \\
\hline \multicolumn{11}{|l|}{$\begin{array}{l}\text { Enfermeira na atenção } \\
\text { ao parto }\end{array}$} \\
\hline Não & 93,1 & 96,8 & 3,7 & 1,04 & 0,016 & 89,4 & 95,0 & 5,6 & 1,06 & $<0,001$ \\
\hline Sim & 94,4 & 98,1 & 3,7 & 1,04 & $<0,001$ & 87,8 & 95,2 & 7,4 & 1,08 & $<0,001$ \\
\hline \multicolumn{11}{|l|}{$\begin{array}{l}\text { Presença de quartos } \\
\operatorname{PPP}^{\star \star}\end{array}$} \\
\hline Não & - & 97,6 & - & - & - & - & 95,2 & - & - & - \\
\hline Sim & - & 98,8 & - & - & - & - & 94,7 & - & - & - \\
\hline \multicolumn{11}{|l|}{$\begin{array}{l}\text { Acompanhante } \\
\text { hospitalar }\end{array}$} \\
\hline Não ou parcialmente & 93,2 & 96,7 & 3,5 & 1,04 & 0,005 & 88,0 & 93,7 & 5,7 & 1,06 & $<0,001$ \\
\hline Todo o tempo & 95,6 & 98,1 & 2,5 & 1,03 & 0,001 & 92,8 & 95,9 & 3,1 & 1,03 & 0,014 \\
\hline \multicolumn{11}{|c|}{ Características das puérperas } \\
\hline \multicolumn{11}{|l|}{ Idade } \\
\hline$\leq 19$ anos & 92,9 & 98,4 & 5,5 & 1,06 & $<0,001$ & 90,0 & 96,0 & 6,0 & 1,07 & $<0,001$ \\
\hline 20 a 34 anos & 94,1 & 97,8 & 3,7 & 1,04 & $<0,001$ & 88,7 & 95,1 & 6,4 & 1,07 & $<0,001$ \\
\hline 35 ou mais & 93,3 & 96,3 & 3,0 & 1,03 & 0,109 & 86,3 & 93,8 & 7,5 & 1,09 & 0,001 \\
\hline \multicolumn{11}{|l|}{ Raça/Cor } \\
\hline Branca & 94,1 & 97,8 & 3,7 & 1,04 & 0,001 & 89,6 & 95,0 & 5,4 & 1,06 & $<0,001$ \\
\hline Preta & 94,8 & 97,2 & 2,4 & 1,03 & 0,073 & 85,4 & 94,2 & 8,8 & 1,10 & $<0,001$ \\
\hline Parda & 93,4 & 98,0 & 4,6 & 1,05 & $<0,001$ & 88,5 & 95,4 & 6,9 & 1,08 & $<0,001$ \\
\hline
\end{tabular}


Tabela 4. Prevalência de amamentação nas primeiras 24 horas de vida (\%) e diferenças entre os estudos NB e ARC segundo características hospitalares e maternas, para o parto vaginal e cesariana.

\begin{tabular}{|c|c|c|c|c|c|c|c|c|c|c|}
\hline \multicolumn{11}{|l|}{ Escolaridade } \\
\hline EF incompleto & 92,3 & 95,8 & 3,5 & 1,04 & 0,026 & 85,6 & 96,3 & 10,7 & 1,12 & $<0,001$ \\
\hline EF completo & 94,0 & 98,3 & 4,3 & 1,05 & $<0,001$ & 89,1 & 94,7 & 5,6 & 1,06 & $<0,001$ \\
\hline EM completo & 94,7 & 98,1 & 3,4 & 1,04 & $<0,001$ & 89,8 & 95,1 & 5,3 & 1,06 & $<0,001$ \\
\hline ES completo e mais & 96,4 & 95,9 & $-0,5$ & 1,00 & 0,839 & 90,6 & 95,6 & 5,0 & 1,05 & 0,027 \\
\hline \multicolumn{11}{|l|}{ Vive com companheiro } \\
\hline Não & 93,2 & 97,8 & 4,6 & 1,05 & $<0,001$ & 85,5 & 92,4 & 6,9 & 1,08 & $<0,001$ \\
\hline Sim & 93,9 & 97,8 & 3,9 & 1,04 & $<0,001$ & 89,5 & 95,7 & 6,2 & 1,07 & $<0,001$ \\
\hline \multicolumn{11}{|l|}{ Paridade } \\
\hline Primípara & 93,2 & 97,5 & 4,3 & 1,05 & $<0,001$ & 88,7 & 94,0 & 5,3 & 1,06 & $<0,001$ \\
\hline 1-2 partos anteriores & 94,3 & 98,3 & 4,0 & 1,04 & $<0,001$ & 89,1 & 96,5 & 7,4 & 1,08 & $<0,001$ \\
\hline $\begin{array}{l}3 \text { ou mais partos } \\
\text { anteriores }\end{array}$ & 93,5 & 97,4 & 3,9 & 1,04 & 0,003 & 85,9 & 93,5 & 7,6 & 1,09 & 0,003 \\
\hline
\end{tabular}

Tabela 5. Prevalência aspiração de vias aéreas superiores (\%) e diferenças entre os estudos NB e ARC segundo características hospitalares e maternas, para o parto vaginal e cesariana.

\begin{tabular}{|c|c|c|c|c|c|c|c|c|c|c|}
\hline & \multicolumn{5}{|c|}{ Vaginal } & \multicolumn{5}{|c|}{ Cesariana } \\
\hline & $\begin{array}{c}\text { NB } \\
(\mathbf{n}= \\
8.921)\end{array}$ & $\begin{array}{c}\text { ARC } \\
(n= \\
4.568)\end{array}$ & $\begin{array}{c}\text { Dif. } \\
\text { Absoluta }\end{array}$ & Razão & $\begin{array}{c}\text { P- } \\
\text { valor }^{*}\end{array}$ & $\begin{array}{c}\text { NB } \\
(\mathbf{n}= \\
7.073)\end{array}$ & $\begin{array}{c}\text { ARC } \\
(\mathbf{n}= \\
3.478)\end{array}$ & $\begin{array}{c}\text { Dif. } \\
\text { Absoluta }\end{array}$ & Razão & $\begin{array}{c}\text { P- } \\
\text { valor }^{*}\end{array}$ \\
\hline Total & 69,6 & 21,2 & $-48,4$ & 0,30 & $<0,001$ & 73,7 & 31,4 & $-42,3$ & 0,43 & $<0,001$ \\
\hline \multicolumn{11}{|c|}{ Características hospitalares } \\
\hline \multicolumn{11}{|l|}{ Região } \\
\hline Norte & 66,5 & 14,9 & $-51,6$ & 0,22 & $<0,001$ & 78,8 & 20,0 & $-58,8$ & 0,25 & $<0,001$ \\
\hline Nordeste & 60,7 & 26,1 & $-34,6$ & 0,43 & $<0,001$ & 66,4 & 37,1 & $-29,3$ & 0,56 & $<0,001$ \\
\hline Sudeste & 77,2 & 21,2 & $-56,0$ & 0,27 & $<0,001$ & 78,1 & 31,2 & $-46,9$ & 0,40 & $<0,001$ \\
\hline Sul & 71,5 & 16,5 & $-55,0$ & 0,23 & $<0,001$ & 73,4 & 27,6 & $-45,8$ & 0,38 & $<0,001$ \\
\hline Centro-oeste & 59,9 & 20,3 & $-39,6$ & 0,34 & $<0,001$ & 68,0 & 35,5 & $-32,5$ & 0,52 & 0,001 \\
\hline \multicolumn{11}{|l|}{ Tipo } \\
\hline SUS & 69,5 & 19,2 & $-50,3$ & 0,28 & $<0,001$ & 72,5 & 25,1 & $-47,4$ & 0,35 & $<0,001$ \\
\hline Misto & 69,8 & 24,5 & $-45,3$ & 0,35 & $<0,001$ & 74,5 & 39,7 & $-34,8$ & 0,53 & $<0,001$ \\
\hline \multicolumn{11}{|l|}{ Localidade } \\
\hline Não capital & 70,5 & 23,9 & $-46,6$ & 0,34 & $<0,001$ & 73,7 & 35,0 & $-38,7$ & 0,48 & $<0,001$ \\
\hline Capital & 68,3 & 17,3 & $-51,0$ & 0,25 & $<0,001$ & 73,8 & 25,4 & $-48,4$ & 0,34 & $<0,001$ \\
\hline \multicolumn{11}{|l|}{ Volume de Parto } \\
\hline até 999 & 76,0 & 17,7 & $-58,3$ & 0,23 & $<0,001$ & 71,7 & 33,3 & $-38,4$ & 0,46 & $<0,001$ \\
\hline 1000 a 2999 & 68,7 & 24,5 & $-44,2$ & 0,36 & $<0,001$ & 73,7 & 35,6 & $-38,1$ & 0,48 & $<0,001$ \\
\hline$\geq 3000$ & 69,0 & 19,4 & $-49,6$ & 0,28 & $<0,001$ & 74,6 & 27,5 & $-47,1$ & 0,37 & $<0,001$ \\
\hline \multicolumn{11}{|l|}{ IHAC } \\
\hline Não & 69,1 & 21,6 & $-47,5$ & 0,31 & $<0,001$ & 72,9 & 32,9 & $-40,0$ & 0,45 & $<0,001$ \\
\hline $\operatorname{Sim}$ & 70,2 & 20,6 & $-49,6$ & 0,29 & $<0,001$ & 74,9 & 28,4 & $-46,5$ & 0,38 & $<0,001$ \\
\hline \multicolumn{11}{|c|}{ Enfermeira na atenção ao parto } \\
\hline Não & 66,9 & 21,9 & $-45,0$ & 0,33 & $<0,001$ & 68,1 & 34,3 & $-33,8$ & 0,50 & $<0,001$ \\
\hline Sim & 72,5 & 21,0 & $-51,5$ & 0,29 & $<0,001$ & 80,6 & 30,3 & $-50,3$ & 0,38 & $<0,001$ \\
\hline
\end{tabular}


Tabela 5. Prevalência aspiração de vias aéreas superiores (\%) e diferenças entre os estudos NB e ARC segundo características hospitalares e maternas, para o parto vaginal e cesariana.

\begin{tabular}{|c|c|c|c|c|c|c|c|c|c|c|}
\hline & \multicolumn{5}{|c|}{ Vaginal } & \multicolumn{5}{|c|}{ Cesariana } \\
\hline & $\begin{array}{c}\text { NB } \\
(\mathbf{n}= \\
8.921)\end{array}$ & $\begin{array}{c}\text { ARC } \\
(n= \\
4.568)\end{array}$ & $\begin{array}{c}\text { Dif. } \\
\text { Absoluta }\end{array}$ & Razão & $\begin{array}{c}\text { P- } \\
\text { valor }^{*}\end{array}$ & $\begin{array}{c}\text { NB } \\
(\mathbf{n}= \\
7.073)\end{array}$ & $\begin{array}{c}\text { ARC } \\
(\mathbf{n}= \\
3.478)\end{array}$ & $\begin{array}{c}\text { Dif. } \\
\text { Absoluta }\end{array}$ & Razão & $\begin{array}{c}\text { P- } \\
\text { valor }^{*}\end{array}$ \\
\hline \multicolumn{11}{|l|}{ Presença de quartos PPP** } \\
\hline Não & - & 22,5 & - & - & - & - & 31,5 & - & - & - \\
\hline Sim & - & 15,1 & - & - & - & - & 30,3 & - & - & - \\
\hline \multicolumn{11}{|l|}{ Acompanhante hospitalar } \\
\hline Não ou parcialmente & 70,4 & 26,8 & $-43,6$ & 0,38 & $<0,001$ & 73,4 & 32,8 & $-40,6$ & 0,45 & $<0,001$ \\
\hline Todo o tempo & 66,7 & 19,7 & $-47,0$ & 0,30 & $<0,001$ & 75,5 & 30,6 & $-44,9$ & 0,41 & $<0,001$ \\
\hline \multicolumn{11}{|l|}{ Características das puérperas } \\
\hline \multicolumn{11}{|l|}{ Idade } \\
\hline$\leq 19$ anos & 67,3 & 23,3 & $-44,0$ & 0,35 & $<0,001$ & 72,7 & 31,9 & $-40,8$ & 0,44 & $<0,001$ \\
\hline 20 a 34 anos & 70,3 & 20,4 & $-49,9$ & 0,29 & $<0,001$ & 73,7 & 31,7 & $-42,0$ & 0,43 & $<0,001$ \\
\hline 35 ou mais & 71,1 & 22,6 & $-48,5$ & 0,32 & $<0,001$ & 75,5 & 29,4 & $-46,1$ & 0,39 & $<0,001$ \\
\hline \multicolumn{11}{|l|}{ Raça/Cor } \\
\hline Branca & 72,3 & 21,0 & $-51,3$ & 0,29 & $<0,001$ & 75,6 & 30,4 & $-45,2$ & 0,40 & $<0,001$ \\
\hline Preta & 66,3 & 17,4 & $-48,9$ & 0,26 & $<0,001$ & 73,1 & 30,1 & $-43,0$ & 0,41 & $<0,001$ \\
\hline Parda & 69,0 & 22,2 & $-46,8$ & 0,32 & $<0,001$ & 72,6 & 32,1 & $-40,5$ & 0,44 & $<0,001$ \\
\hline \multicolumn{11}{|l|}{ Escolaridade } \\
\hline EF incompleto & 66,9 & 19,7 & $-47,2$ & 0,29 & $<0,001$ & 72,0 & 31,9 & $-40,1$ & 0,44 & $<0,001$ \\
\hline EF completo & 69,3 & 21,5 & $-47,8$ & 0,31 & $<0,001$ & 72,7 & 31,4 & $-41,3$ & 0,43 & $<0,001$ \\
\hline EM completo & 73,1 & 21,4 & $-51,7$ & 0,29 & $<0,001$ & 74,9 & 31,5 & $-43,4$ & 0,42 & $<0,001$ \\
\hline ES completo e mais & 66,9 & 19,7 & $-47,2$ & 0,29 & $<0,001$ & 76,9 & 30,5 & $-46,4$ & 0,40 & $<0,001$ \\
\hline \multicolumn{11}{|l|}{ Vive com companheiro } \\
\hline Não & 70,6 & 21,2 & $-49,4$ & 0,30 & $<0,001$ & 77,0 & 28,3 & $-48,7$ & 0,37 & $<0,001$ \\
\hline Sim & 69,4 & 21,2 & $-48,2$ & 0,31 & $<0,001$ & 73,1 & 32,1 & $-41,0$ & 0,44 & $<0,001$ \\
\hline \multicolumn{11}{|l|}{ Paridade } \\
\hline Primípara & 70,1 & 18,7 & $-51,4$ & 0,27 & $<0,001$ & 73,9 & 29,7 & $-44,2$ & 0,40 & $<0,001$ \\
\hline 1-2 partos anteriores & 70,5 & 24,5 & $-46,0$ & 0,35 & $<0,001$ & 73,9 & 33,8 & $-40,1$ & 0,46 & $<0,001$ \\
\hline 3 ou mais partos anteriores & 65,8 & 20,2 & $-45,6$ & 0,31 & $<0,001$ & 71,9 & 28,5 & $-43,4$ & 0,40 & $<0,001$ \\
\hline
\end{tabular}

${ }^{\star}$ P-valor $<0,05$ no teste chi-quadrado de Pearson. ${ }^{*}$ Quartos com cama PPP: pré-parto, parto e pós-parto.

A amamentação nas primeiras $24 \mathrm{~h}$ partiu de prevalências altas no NB, próximas a $95 \%$ nos partos vaginais e a $90 \%$ nas cesarianas, chegando a quase $100 \%$ e $95 \%$ na ARC, respectivamente. Não foram observadas alterações relevantes na prevalência da amamentação entre as variáveis estudadas, nem aumentos expressivos entre os dois estudos (Tabela 4).

A aspiração de rotina das vias aéreas do $\mathrm{RN}$ reduziu para um terço nos partos vaginais e para menos da metade nas cesarianas. No entanto, como a queda foi mais expressiva nos partos vaginais, a diferença relativa entre os tipos de parto aumentou. No estudo da ARC, foi menor a aspi- ração das vias aéreas dos RN (de partos vaginais) quando quartos PPP estavam presentes no hospital (Tabela 5).

\section{Discussão}

A comparação entre quatro práticas do cuidado ao RN saudável no momento do nascimento em hospitais inseridos no SUS, segundo o tipo de parto, verificadas no NB e na ARC evidenciou um padrão nacional de melhora com maior utilização de práticas desejáveis contato pele a pele, amamentação na primeira hora de vida e amamen- 
tação nas primeiras 24 horas de vida e redução de uma prática que não é considerada adequada (aspiração rotineira de vias aéreas superiores).

A melhoria das práticas de atenção ao RN saudável verificada neste estudo deve ser discutida levando-se em conta o contexto de mudanças no modelo de atenção ao parto e nascimento e ao $\mathrm{RN}$ de risco habitual, foco central das ações do MS para atenção obstétrica e neonatal traduzidas em iniciativas em curso desde a década de 1990 e intensificadas com o Plano de Qualificação de Maternidades (PQM) (voltado para as regiões Norte e Nordeste) e com a implantação da RC, com abrangência nacional ${ }^{7,16}$.

Como iniciativa de âmbito federal, a implantação da RC é acompanhada também por políticas e programas no âmbito dos estados e municípios, ações de pesquisadores e de profissionais assim como de movimentos sociais e de mulheres em busca da garantia de práticas clínicas baseadas em evidências. São ações que, ao longo do período entre os estudos, caminharam com o mesmo objetivo de melhoria de práticas compondo uma nova concepção na atenção ao parto e nascimento.

Os resultados encontrados após um intervalo de 6 anos do mapeamento das práticas neonatais realizado pelo NB, registram a expressiva redução de uma intervenção desnecessária em RN saudáveis (aspiração de vias aéreas superiores) e a maior utilização das três práticas analisadas, com maior variação positiva para as que eram menos prevalentes em 2011: contato pele a pele e amamentação na primeira hora.

Considerando que a estrutura da maternidade para o trabalho de parto e parto influencia a experiência da mulher e o padrão de práticas de atenção ao $\mathrm{RN}$ saudável ${ }^{7,17-19}$, a melhoria de práticas neonatais observada é coerente com a melhoria estrutural. Como sinalizadores desse impacto destaca-se a disponibilidade de enfermagem obstétrica. Nas maternidades com disponibilidade de quarto PPP, variável analisada apenas na ARC, o estudo confirma tal influência ao evidenciar melhores resultados nas práticas neonatais nas maternidades que têm essa característica.

Da mesma forma, o significativo aumento (300\%) da presença do acompanhante na ARC quando comparado com esse mesmo dado no NB é também um sinalizador da adequação da estrutura e dos processos de cuidado obstétrico no qual os esforços para a melhoria da atenção ao RN saudável estão situados.

A existência ou não de PPP e a atuação da enfermagem obstétrica são, portanto, compreen- didas, nesta análise das práticas de atendimento ao RN saudável, como reveladoras de contextos de serviços que já haviam, no mínimo, iniciado a incorporação de ações concretas para a mudança de modelo de atenção baseado em evidências e praticado nos países com melhores indicadores perinatais $^{20-23}$.

Um outro elemento a ser destacado, por sua influência direta na definição do padrão de práticas neonatais no momento do nascimento, é o Programa de Reanimação Neonatal (PRN), coordenado no Brasil pela Sociedade Brasileira de Pediatria. O referido programa tem ampla capilaridade nacional e tem sido responsável pela disseminação de práticas clínicas adequadas, indicando a manutenção do RN saudável junto à sua mãe, propiciando o contato pele a pele e o aleitamento na primeira hora. O PRN reitera também que não há necessidade de aspiração rotineira das vias aéreas para esse grupo de neonatos ${ }^{8}$.

$\mathrm{O}$ aumento na proporção do contato pele a pele nos hospitais IHAC e não IHAC, tanto nos partos vaginais quanto nas cesarianas, com redução nas diferenças entre os dois tipos de hospital, indicam o alcance das ações da RC e das estratégias de disseminação do conhecimento mesmo em hospitais que ainda não possuem a certificação de HAC. Merece ser destacado que na IHAC, estratégia priorizada pelo MS desde 1992, um dos maiores desafios tem se localizado no cumprimento do Passo 4, que advoga a facilitação do contato pele a pele imediato e ininterrupto e o apoio para as mães iniciarem a amamentação o mais rápido possível após o nascimento ${ }^{24,25}$.

Mesmo considerando que, em 2009, o conjunto de recomendações da IHAC foi revisado pela Organização Mundial de Saúde e a elas foram acrescentadas abordagens mais abrangentes relativas às boas práticas endereçadas também à mãe $e^{26,27}$, como observado neste estudo, é possível discutir que os esforços e os movimentos de implantação de um modelo que abrange os diferentes momentos da linha de cuidado parece ter apresentado impacto positivo e de grande potência, contribuindo, inclusive, para o alcance de objetivos de estratégias mais focalizadas como a IHAC.

$\mathrm{O}$ aumento do contato pele a pele nas regiões Norte e Nordeste, com ênfase no expressivo aumento no Nordeste, e aproximação às prevalências encontradas para as regiões Sul e Sudeste, que apresentavam as melhores proporções no NB, é um importante resultado. Esse achado pode ser compreendido como decorrente da consolidação de estratégias de melhoria de prá- 
ticas que vinham sendo implementadas desde o PQM e Redes Perinatais da Amazônia Legal (AL) e Nordeste (NE) - PQM em 2009 e que foram intensificadas com a RC que incluía estratégias específicas para essas regiões ${ }^{28,29}$.

O contato pele a pele e a amamentação na primeira hora apresentaram crescimento nos dois estudos, no entanto a frequência da amamentação na primeira hora se mantém muito menor: cerca de metade da prevalência do contato pele a pele. Esse cenário ainda é bastante diverso do verificado em países como o Canada onde apenas $8 \%$ das maternidades não tem a prática do contato mãe-bebê imediato após o nascimento ${ }^{30}$. Além disso, ao contrário do que aconteceu com o contato pele a pele, a diferença na prevalência de amamentação na primeira hora entre partos vaginais e cesariana aumentou entre os dois estudos. Esse resultado evidencia a importância de manutenção dos esforços para a realização do contato pele a pele, que ainda não atinge a totalidade dos nascimentos, mas aponta também para a necessidade de estratégias específicas para a oferta do seio no momento do nascimento e de intensificação de esforços especificamente direcionados para a implantação de boas práticas para os RN saudáveis nascidos de cesariana.

As mulheres de cor da pele preta, em comparação às brancas, tiveram um aumento mais expressivo do contato pele a pele e de amamentação na primeira hora de vida para os partos vaginais. Para ambas as práticas, as mulheres pretas partiram de prevalências inferiores no NB e chegaram a ultrapassar as prevalências das mulheres brancas no estudo da ARC. Este achado é compatível ao descrito por Leal et. al. ${ }^{30}$, que encontrou uma redução importante das iniquidades socioeconômicas relativas às boas práticas durante o trabalho de parto e parto, numa comparação semelhante à aqui realizada. Em contrapartida, para as cesarianas, o aumento de ambas as práticas foi superior nas mulheres brancas que nas pardas ou pretas, revelando um aumento das iniquidades no parto cesáreo. Mais estudos são necessários para uma maior compreensão da dinâmica de introdução das boas práticas na atenção ao parto e ao recém-nascido no país, que pode variar conforme características maternas e pelo tipo de parto.
Quanto à amamentação nas primeiras 24 horas, cabe mencionar que, apesar de já ter sido alta a prevalência no estudo NB, houve espaço para aumento na ARC, expressando resultados de ações das políticas pública, que devem ser mantidas e ampliadas.

Uma limitação da presente análise refere-se às diferenças na representatividade da amostra dos estudos comparados. O estudo da ARC envolveu o número total de maternidades que recebeu a intervenção da $\mathrm{RC}$, tendo representatividade nacional para este grupo de maternidades. Já o estudo NB teve representatividade nacional entre todas as maternidades com $\geq 500$ partos/ ano do país. Embora tenham sido incluídas maternidades com menos de 500 partos/ano na ARC, o que não ocorreu no NB, é pouco provável que os resultados destas maternidades tenham afetado de forma significativa a melhoria observada nas práticas assistenciais ${ }^{7}$. Ademais, a proporção de mulheres com parto em hospitais com menos de 1.000 partos/ano foi menor no estudo da ARC do que no NB. Uma outra limitação foi o número reduzido de práticas no $\mathrm{RN}$ que puderam ser comparadas entre os dois estudos, dado que o uso rotineiro de $\mathrm{O}_{2}$ inalatório e aspiração gástrica foram coletados apenas no estudo NB, e o clampeamento oportuno do cordão umbilical, mais recentemente discutido, não foi abordado em nenhum dos estudos.

No Brasil, onde a maioria dos partos é hospitalar, observa-se, uma melhora no cuidado ao RN saudável logo após o nascimento. Os resultados deste estudo evidenciam que diretrizes baseadas na melhor evidência para atendimento ao RN saudável estão mais presentes na prática clínica nos hospitais públicos incluídos na ARC comparado ao encontrado em hospitais públicos e conveniados ao SUS no NB. A despeito disso, ainda persistem importantes desafios para que as boas práticas sejam garantidas para a totalidade desse grupo, em particular em relação nos nascimentos por cesariana. A continuidade e o fortalecimento de políticas públicas voltadas para a qualificação da atenção durante a gestação, parto e nascimento e a disseminação de conhecimento para a melhoria da prática clínica são fundamentais para o alcance desse objetivo. 


\section{Colaboradores}

MASM Gomes, APE Pereira, SDA Bittencourt, LCR Augusto, F Lamy-Filho, ZC Lamy, C Magluta e ME Moreira participaram da concepção, planejamento e análise dos dados; da redação ou revisão crítica da versão final e da aprovação final da versão a ser publicada; sendo responsáveis por todos os aspectos do trabalho na garantia da exatidão e integridade de seu conteúdo.

\section{Referências}

1. Moreira MEL, Gama SGN, Pereira APE, Silva AAM, Lansky S, Pinheiro RS, Gonçalves AC, Leal MC. Práticas de atenção hospitalar ao recém-nascido saudável no Brasil. Cad Saude Publica [Internet]. 2014 [cited 2020 Jan 29]; 30(Supl. 1):S128-S139. Available from: http://www.scielo.br/scielo.php?script=sci_arttext\&pid=S0102-311X2014001300019\&lng=en. http:// dx.doi.org/10.1590/0102-311X00145213

2. Boccolini CS, Carvalho ML, Oliveira MIC, Leal MC, Carvalho MS. Fatores que interferem no tempo entre o nascimento e a primeira mamada. Cad Saude Publica [Internet]. 2008 Nov [cited 2020 Jan 29]; 24(11):2681-2694. Available from: http:// www.scielo.br/scielo.php?script=sci_arttext\&pi$\mathrm{d}=\mathrm{S} 0102-311 \mathrm{X} 2008001100023 \& \operatorname{lng}=\mathrm{en} . \quad \mathrm{http}: / / \mathrm{dx}$. doi.org/10.1590/S0102-311X2008001100023.

3. Boccolini CS, Carvalho ML, Oliveira MIC, Vasconcellos AGG. Fatores associados à amamentação na primeira hora de vida. Rev Saude Publica [Internet]. $2011 \mathrm{Feb}$ [cited 2020 Jan 24]; 45(1):69-78. Available from: http://www.scielo.br/scielo.php?script=sci_arttext\&pid=S0034-89102011000100008\&lng=en. Epub Nov 12, 2010. http://dx.doi.org/10.1590/S003489102010005000051

4. Boccolini CS, Carvalho ML, Oliveira MIC, Pérez-Escamilla R. Breastfeeding during the first hour of life and neonatal mortality. J. Pediatr. [Internet]. 2013 Apr [cited 2020 Jan 24]; 89(2):131-136. Available from: http://www.scielo.br/scielo.php?script=sci_arttext\&pid=S0021-75572013000200005\&lng=en

5. Pasche DF, Vilela MEA, Almeida, PVB, Giovanni MD, Franco Netto TL. Rede Cegonha: desafios de mudanças culturais nas práticas obstétricas e neonatais. Revista Divulgação em Saúde para Debate 2014; (2):5871.

6. Brasil. Ministério da Saúde (MS). Secretaria de Atenção Primária à Saúde [https://aps.saude.gov.br/] Rede Cegonha [cited 2020 Jan 29]. Available from: https:// aps.saude.gov.br/ape/cegonha

7. Leal MC, Bittencourt SA, Esteves PAP, Ayres BVS, Silva LBRAA, Thomaz EBAF, Lamy ZC, Nakamura-Pereira M, Torres JA, Gama SGN, Domingues RMSM, Vilela MEA. Avanços na assistência ao parto no Brasil: resultados preliminares de dois estudos avaliativos. Cad Saude Publica [Internet]. 2019 [cited 2020 Jan 24]; 35(7):e00223018. Available from: http:// www.scielo.br/scielo.php?script $=$ sci_arttext\&pi$\mathrm{d}=$ S0102-311X2019000905002\&lng=en

8. ALmeida MFB, Guinsburg R. Reanimação do recémnascido $\geq 34$ semanas em sala de parto: Diretrizes 2016 da Sociedade Brasileira de Pediatria, 26 de janeiro de 2016. [cited 2020 Jan 24]. Available from: www. sbp.com.br/reanimacao.

9. Almeida MFB, Guinsburg R, Costa JO, Anchieta LM, Freire LMS. Ensino da reanimação neonatal em maternidades públicas das capitais brasileiras. J Pediatr [Internet]. 2005 June [cited 2020 Jan 30]; 81(3):233-239. Available from: http:// www.scielo.br/scielo.php?script $=$ sci_arttext\&pi$\mathrm{d}=$ S0021-75572005000400010\&lng=en. http://dx.doi. org/10.1590/S0021-75572005000400010. 
10. Perlman JM, Wyllie J, Kattwinkel J, Wyckoff MH, Aziz K, Guinsburg R, Kim HS, Liley HG, Mildenhall L, Simon WM, Szyld E, Tamura M, Velaphi S; Neonatal Resuscitation Chapter Collaborators. Part 7: Neonatal Resuscitation: 2015 International Consensus on Cardiopulmonary Resuscitation and Emergency Cardiovascular Care Science With Treatment Recommendations. Circulation 2015; 132(16 Supl. 1):S204-241.

11. World Health Organization (WHO). WHO recommendations: intrapartum care for a positive childbirth experience. Geneva: WHO; 2018. [acessado $2020 \mathrm{Jul}$ 5]. Disponível em: https://www.who.int/publications/i/item/9789241550215

12. Mercer JS, Erickson-Owens DA, Graves B, Haley MM. Práticas baseadas em evidências para a transição de feto a recém-nascido. Revista Eletrônica Tempus Actas Saúde Coletiva [online]. 2010. [acessado $2020 \mathrm{Jul}$ 10]. Disponível em: http://www.tempusactas.unb.br/ index.php/tempus/article/view/845

13. Ehret DY, Patterson JK, Bose CL. Improving Neonatal Care: A Global Perspective. Clin Perinatol 2017; 44(3):567-582.

14. Canada. Public Health Agency of Canada. Perinatal Health Indicators for Canada 2017: A Report of the Canadian Perinatal Surveillance System. Ottawa: Public Health Agency of Canada; 2017.

15. Euro-Peristat Project. European Perinatal Health Report. Core indicators of the health and care of pregnant women and babies in Europe in in 2015. [Relatório]. 2018. [cited 2020 Jan 29]. Available from: https:// www.europeristat.com/index.php/reports/european -perinatal-health-report-2015.html

16. Euro-Peristat Project, with SCPE, EUROCAT, EURONEOSTAT. European Perinatal Health Report. 2008. [cited 2020 Jan 29]. Available from: https://www.europeristat.com

17. Brasil. Ministério da Saúde (MS). Portaria de Consolidação no 3, de 28 de setembro de 2017. Consolidação das normas sobre o financiamento e a transferência dos recursos federais para as ações e os serviços de saúde do Sistema Único de Saúde. Diário Oficial da União 2017; 3 out

18. Vilela MEA, Leal MC, Thomaz EBAF, Gomes MASM, Bittencourt SDA, Gama SGN, Silva LBRAA, Lamy ZC. Avaliação da atenção ao parto e nascimento nas maternidades da Rede Cegonha: Os caminhos metodológicos. Cien Saude Colet 2021; 26(3):789-800.

19. Leal MC, Gama SGN. Nascer no Brasil. Cad Saude Publica [Internet]. 2014 [citado 2020 Jan 29]; 30(Supl. 1):S5-S5. Disponível em: http:// www.scielo.br/scielo.php?script=sci_arttext\&pi$\mathrm{d}=\mathrm{S} 0102-311 \mathrm{X} 2014001300001 \& \operatorname{lng}=\mathrm{pt} . \quad \mathrm{http} / / / \mathrm{dx}$. doi.org/10.1590/0102-311XED01S114.

20. Gomes MASM. Método Canguru no contexto das políticas públicas para atenção à gestação, parto, nascimento e recém-nascido no Brasil In: Sanches MTC, Costa R, Azevedo VMGO, Morsch DS, Lamy ZC, organizadores. Método Canguru no Brasil: 15 anos de política pública. São Paulo: Instituto de Saúde; 2015. (Temas em saúde coletiva, 19) p. 31-47.
21. Vogt SE, Diniz SG, Tavares CM, Santos NCP, Schneck CA, Zorzam B, Vieira DA, Silva KS, Dias MAB. Características da assistência ao trabalho de parto e parto em três modelos de atenção no SUS, no Município de Belo Horizonte, Minas Gerais, Brasil. Cad Saude Publica [Internet]. 2011 Sep [cited 2020 Jan 24]; 27(9):1789-1800. Available from: http:// www.scielo.br/scielo.php?script=sci_arttext\&pi$\mathrm{d}=$ S0102-311X2011000900012\&lng=en

22. Carvalho VFK, Nalú PC, Busanello J, Gonçalves BG, Rodrigues EF, Azambuja EP. Como os trabalhadores de um Centro Obstétrico justificam a utilização de práticas prejudiciais ao parto normal. Rev. esc. enferm. USP [Internet]. 2012 Feb [cited 2020 Jan 24]; 46(1):30-37. Available from: http:// www.scielo.br/scielo.php?script=sci_arttext\&pi$\mathrm{d}=$ S0080-62342012000100004\&lng=en. http://dx. doi.org/10.1590/S0080-62342012000100004.

23. Carvalho EMP, Amorim FF, Santana LA, Göttems LBD. Avaliação das boas práticas de atenção ao parto por profissionais dos hospitais públicos do Distrito Federal, Brasil. Cien Saude Colet [Internet]. 2019 June [cited 2020 Jan 24]; 24(6):2135-2145. Available from: http://www.scielo.br/scielo.php?script=sci_arttext\&pid=S1413-81232019000602135\&lng=en

24. Sandall J SH, Soltani H, Gates S, Shennan A, Devane D. Midwife-led continuity models versus other models of care for childbearing women. Cochrane Database Syst Rev [Internet]. 2015 [cited 2016 May 11]; 15(9):CD004667. Available from: http://onlinelibrary. wiley.com/doi/10.1002/14651858. CD004667.pub5/ pdf/abstract.

25. World Health Organization (WHO). WHO recommendations: intrapartum care for a positive childbirth experience. Geneva: WHO; 2018.

26. Sousa AMM, Souza KV, Rezende EM, Martins EF, Campos D, Lansky S. Práticas na assistência ao parto em maternidades com inserção de enfermeiras obstétricas, em Belo Horizonte, Minas Gerais. Esc. Anna Nery [Internet]. 2016 June [cited 2020 Jan 24]; 20(2):324-331. Available from: http:// www.scielo.br/scielo.php?script=sci_arttext\&pid= S1414-81452016000200324\&lng=en. http://dx.doi. org/10.5935/1414-8145.20160044

27. Vargens OMC, Silva ACV, Progianti JM. Contribuição de enfermeiras obstétricas para consolidação do parto humanizado em maternidades no Rio de Janeiro-Brasil. Esc. Anna Nery 2017; 21(1):e20170015.

28. Araújo RG, Fonseca V, Oliveira MIC, Ramos EG. External evaluation and self-monitoring of the Babyfriendly Hospital Initiative's maternity hospitals in Brazil. Int Breastfeed J 2019; 1.

29. Matos TA, Souza MS, Santos EKA, Velho MB, Seibert ERC, Martins NM. Contato precoce pele a pele entre mãe e filho: significado para mães e contribuições para a enfermagem. Rev. Bras. Enferm. [Internet]. 2010 Dec [cited 2020 Jan 24]; 63(6):998-1004. Available from: http://www.scielo.br/scielo.php?script=sci_arttext\&pid=S0034-71672010000600020\&lng=en. http:// dx.doi.org/10.1590/S0034-71672010000600020. 
30. Leal MC, Silva AAM, Dias MAB, Gama SGN, Rattner D, Moreira ME, Theme Filha MM, Domingues RMSM, Pereira APE, Torres JA, Bittencourt SDA, D'orsi E, Cunha AJ, Leite AJM, Cavalcante RS, Lansky S, Diniz CSG, CL Szwarcwald. Birth in Brazil: national survey into labour and birth. Reprod Health 2012; 9:15.

Artigo apresentado em 22/04/2020

Aprovado em 19/08/2020

Versão final apresentada em 21/08/2020

Editores-chefes: Romeu Gomes, Antônio Augusto Moura da Silva 